\title{
Impact of tumor size on survival of patients with resected pancreatic ductal adenocarcinoma: a systematic review and meta-analysis
}

\author{
Debang $\mathrm{Li}^{1+}$, Bin $\mathrm{Hu}^{2+}$, Yanming Zhou ${ }^{3^{*}}$ (D), Tao Wan ${ }^{3}$ and Xiaoying $\mathrm{Si}^{3}$
}

\begin{abstract}
Background: The impact of tumor size on prognosis for surgically treated patients with pancreatic ductal adenocarcinoma (PDAC) remains controversial. A systematic review and meta-analysis was performed to evaluate this issue.

Methods: Relevant studies published from January 2000 to June 2017 were identified through EMBASE and PUBMED. Data were pooled for meta-analysis using Review Manager 5.3.

Results: Twenty eight observational studies involving a total of 23,945 patients were included. Tumors $>2 \mathrm{~cm}$ was associated with poor prognosis: the pooled hazard ratio (HR) estimate for overall survival was 1.52 (95\% confidence interval [Cl]: 1.41-1.64; $P<0.0001)$ by univariate analysis and $1.61(95 \% \mathrm{Cl}: 1.35-1.91 ; P<0.0001)$ by multivariate analysis; the pooled HR estimate for disease-free survival was 1.74 (95\% Cl: $1.46-2.07 ; P<0.0001)$ by univariate analysis and $1.38(95 \% \mathrm{Cl}: 1.12-1.68 ; P=0.002)$ by multivariate analysis. When compared with patients with tumors $\leq 2 \mathrm{~cm}$, those with the tumors $>2 \mathrm{~cm}$ had higher incidences of lymph node metastasis, poor tumor differentiation, lymph vessel invasion, vascular invasion, perineural invasion, and positive intraoperative peritoneal cytology.

Conclusion: These data demonstrate that PDAC size $>2 \mathrm{~cm}$ is an independent predictive factor for poor prognosis after surgical resection and associated with more aggressive tumor biology.
\end{abstract}

Keywords: Pancreatic ductal adenocarcinoma, Resection, Size, Prognosis

\section{Background}

Pancreatic ductal adenocarcinoma (PDAC) represents $90 \%$ of pancreatic cancers and is the fifth leading cause of cancer-related death in Western countries. Complete surgical resection is the only option that can offer hope of prolonged survival; however, the long-term survival remains unsatisfactory with a 5 -year survival rate around $20 \%$ because of the high frequency of postoperative disease recurrence [1]. Therefore, it is necessary to identify prognostic factors to help stratify patients for appropriate management categories. Tumor specific factors, such

\footnotetext{
* Correspondence: zhouymsxy@sina.cn

${ }^{\dagger}$ Debang Li and Bin Hu contributed equally to this work.

${ }^{3}$ Department of Hepatobiliary \& Pancreatovascular Surgery, First affiliated

Hospital of Xiamen University, Xiamen, China

Full list of author information is available at the end of the article
}

as the margin status, histological differentiation, lymph node metastasis, and vascular invasion, have been shown to predict poor clinical outcomes $[2,3]$. Tumor size is also a significant prognostic factor and is included in tumor node metastasis system (TNM) classification. According to the American Joint Committee on Cancer (AJCC) staging system for PDAC, the optimum tumor size cutoff value distinguishing $\mathrm{T} 1$ and $\mathrm{T} 2$ disease is $2 \mathrm{~cm}$ [4]. Despite the availability of many publications, the impact of PDAC size on prognosis remains controversial [5, 6]. A systematic review and meta-analysis of the literature was therefore undertaken to investigate this issue.

(c) The Author(s). 2018 Open Access This article is distributed under the terms of the Creative Commons Attribution 4.0 International License (http://creativecommons.org/licenses/by/4.0/), which permits unrestricted use, distribution, and reproduction in any medium, provided you give appropriate credit to the original author(s) and the source, provide a link to the Creative Commons license, and indicate if changes were made. The Creative Commons Public Domain Dedication waiver (http://creativecommons.org/publicdomain/zero/1.0/) applies to the data made available in this article, unless otherwise stated. 


\section{Methods}

Study selection

The present study was performed by following the recommendations of the Preferred Reporting Items for Systematic Reviews and Meta-Analyses (PRISMA) Statement [7]. An electronic search of the PUBMED and EMBASE databases from January 2000 to June 2017 were performed to identify relevant citations. The following keywords were used: "pancreatic cancer", "pancreatic ductal adenocarcinoma", and "prognosis". The reference lists of all retrieved articles were manually reviewed in order to identify additional studies.

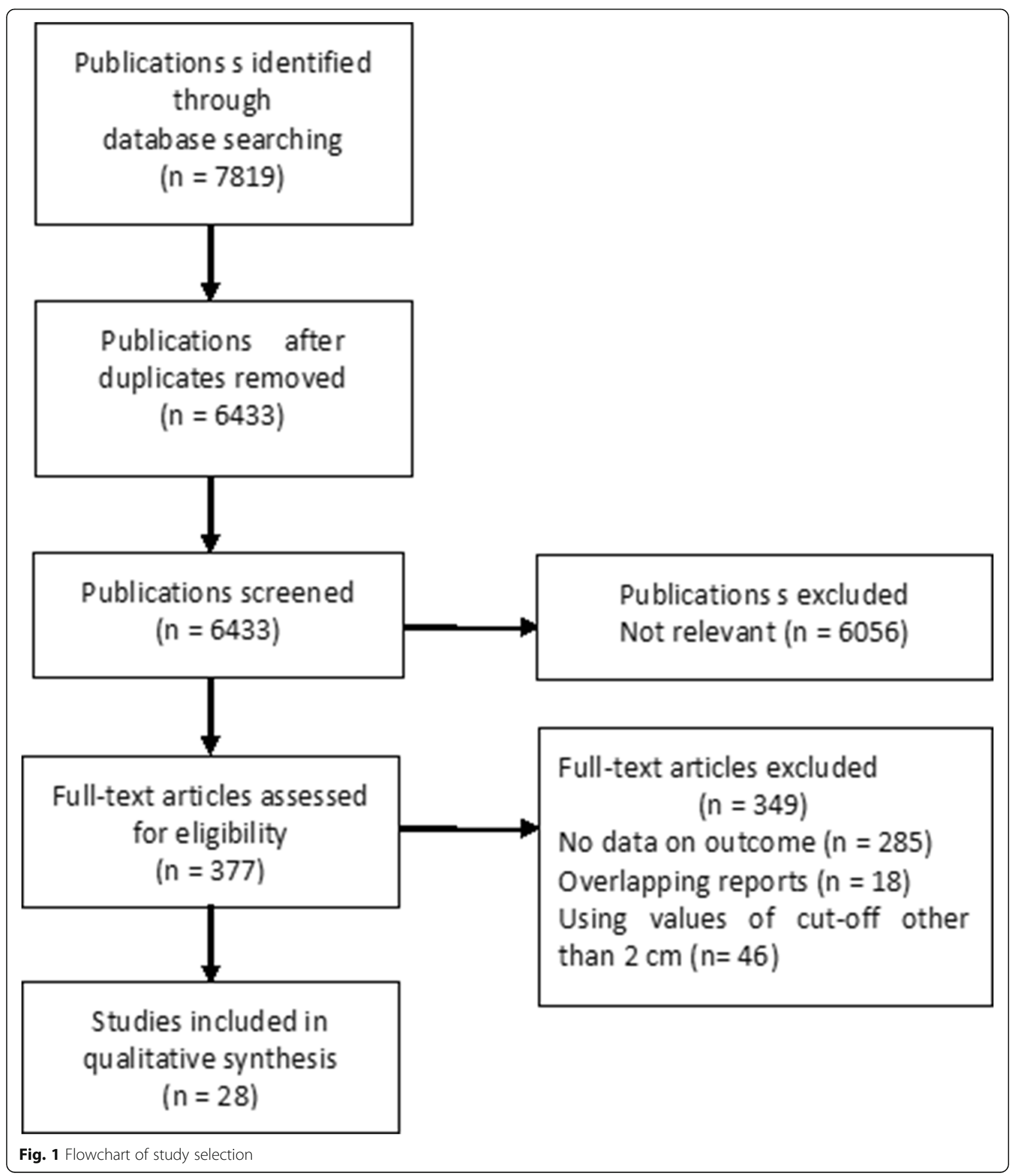




\section{Criteria for inclusion and exclusion}

All original full-text articles reporting the impact of tumor size using a cut-off of $2 \mathrm{~cm}$ on overall survival (OS) or disease-free survival (DFS) in patients with PDAC after resection were considered eligible. Abstracts, letters, editorials and expert opinions, reviews without original data, case reports, non-human studies, non-English language studies, studies using values of cut-off other than $2 \mathrm{~cm}$ for tumor size, and studies that included other periampullary carcinomas (ampullary, duodenal, and biliary) in the same study cohort without separate assessments were excluded.

\section{Data extraction and methodological assessment}

All selected studies were evaluated independently by two investigators (ZY and SX) for data extraction and quality assessment. Disagreement in the evaluation of studies was resolved by discussion and consensus. Parameters extracted included first author, study origin, year of publication, study design, type of resection, pathology, available long-term outcomes, and univariate and multivariate hazard ratios (HR) for OS and DFS.

The level of evidence of each study was categorized according to the Evidence-Based Medicine Levels of Evidence [8].

\section{Statistical methods}

Data for OS and DFS were analyzed using HR with 95\% confidence intervals $(\mathrm{CI})$, and a $\mathrm{HR}>1$ represents a worse outcome. Between-study heterogeneity was assessed with $\mathrm{I}^{2}$ statistics, and a value of $>50 \%$ was considered significant heterogeneity. A funnel plot based on the OS

Table 1 The main characteristics of included studies

\begin{tabular}{|c|c|c|c|c|c|c|c|c|c|c|c|}
\hline Reference & Year & Country & $\mathrm{N}$ & $\begin{array}{l}\mathrm{TS}>2.0 \\
\mathrm{~cm}, \mathrm{n}(\%)\end{array}$ & TRPD/DP/TP & RO R, n (\%) & LNM, n (\%) & PNI, n (\%) & PTD, n (\%) & MOS (Months) & $\begin{array}{l}5-y r \\
\text { OS (\%) }\end{array}$ \\
\hline Meyer [9] & 2000 & Germany & 91 & 67/86 (77.9) & $-/-/-$ & $93(100)$ & $66(72.5)$ & $41(45.1)$ & $14(16.3)$ & 16.8 & 10.5 \\
\hline Ahmad [10] & 2001 & USA & 116 & 70/94 (74.4) & $-/-1-$ & $88(75.8)$ & $73(62.9)$ & - & $61(52.5)$ & 16 & 19 \\
\hline Kim [11] & 2006 & USA & 70 & $50(71.4)$ & $68 / 2 / 0$ & - & $40(57.1)$ & $46(65.7)$ & $26(37.1)$ & 21 & 19 \\
\hline Smith [12] & 2008 & UK & 109 & $81(74.3)$ & 109/0/0 & $80(73.3)$ & $88(80.7)$ & - & $36(33.0)$ & 13.9 & - \\
\hline Chiang [13] & 2009 & Taiwan, & 159 & $123(77.3)$ & $-1-1-$ & $114(71.6)$ & $95(59.7)$ & - & $32(20.1)$ & - & 12.5 \\
\hline Chang [14] & 2009 & Australia & 365 & $281(76.9)$ & 295/70/0 & $233(63.8)$ & $217(59.5)$ & $256(70.1)$ & $98(26.8)$ & 16.8 & 11.4 \\
\hline Kato [15] & 2009 & Japan & 176 & $148(84.1)$ & $176 / 0 / 0$ & $115(65.3)$ & $123(69.8)$ & $145(82.3)$ & $11(6.2)$ & 9.9 & 12.3 \\
\hline Massucco [16] & 2009 & Italy & 77 & $60(77.9)$ & $63 / 0 / 14$ & 59 (76.6) & $59(76.6)$ & $58(75.3)$ & $50(64.9)$ & 16.5 & - \\
\hline Bhatti [17] & 2010 & UK & 84 & $78(92.8)$ & $84 / 0 / 0$ & $49(58.3)$ & $56(66.6)$ & - & $24(28.5)$ & 22 & 13 \\
\hline de Jong [5] & 2011 & USA & 1697 & $1279(75.4)$ & $1640 / 0 / 57$ & $1213(71.8)$ & $1280(75.4)$ & $1126(66.3)$ & $649(38.2)$ & 18.3 & 21.2 \\
\hline Cannon [18] & 2012 & USA & 245 & $213(86.9)$ & $220 / 20 / 0$ & $184(75.1)$ & - & - & $72(29.4)$ & 18.3 & - \\
\hline Petermann [19] & 2013 & Switzerland & 86 & $76(88.3)$ & $86 / 0 / 0$ & 89 (68.6) & $72(83.7)$ & - & - & 16.8 & - \\
\hline Yamada [20] & 2013 & Japan & 390 & $312(80.0)$ & 288/71/31 & - & $277(71.0)$ & - & - & - & - \\
\hline Buc [21] & 2014 & France, & 306 & - & $242 / 45 / 19$ & $195(72.5)$ & $214(71.3)$ & $212(83.8)$ & - & 34 & 32 \\
\hline Elberm [22] & 2015 & UK & 1070 & - & 1070/0/0 & $482(45.9)$ & $757(70.7)$ & - & - & 18.5 & - \\
\hline Iwagami [23] & 2015 & Japan & 39 & $27(69.2)$ & $-1-1-$ & - & $14(35.9)$ & $34(87.2)$ & $3(7.6)$ & - & - \\
\hline Liu [24] & 2015 & USA & 411 & $242(58.9)$ & $411 / 0 / 0$ & $379(92.2)$ & $223(54.3 \%)$ & - & $150(36.5)$ & - & - \\
\hline Okumura [25] & 2015 & Japan & 230 & - & $155 / 66 / 9$ & $190(82.6)$ & 135 (58.7). & - & $33(14.3)$ & - & - \\
\hline Yamamoto [26] & 2015 & Japan & 195 & $156(80.0)$ & $123 / 61 / 11$ & $138(70.7)$ & $145(74.3)$ & $108(55.3)$ & - & 27.1 & 34.5 \\
\hline $\operatorname{Lin}[27]$ & 2016 & China & 233 & $189(81.1)$ & 233/0/0 & $196(84.1)$ & $161(69.1)$ & - & $147(63.1)$ & - & 19.0 \\
\hline Abe [28] & 2017 & Japan & 355 & $273(76.9)$ & $215 / 98 / 22$ & $282(79.4)$ & $223(62.8)$ & $282(79.4)$ & $137(38.5)$ & - & - \\
\hline Ansari [29] & 2017 & USA & 15,398 & 12,725 (82.6) & $-1-1-$ & - & - & - & - & - & 16.1 \\
\hline Chikamoto [30] & 2017 & Japan & 138 & $66(47.8)$ & $138 / 0 / 0$ & - & $46(33.3)$ & - & $10(7.2)$ & - & - \\
\hline Marchegiani [6] & 2017 & Italy, USA & 1507 & $1183(78.5)$ & $1179 / 268 / 59$ & $840(55.7)$ & $1149(76.2)$ & 1376 (91.3) & 468 (31.1) & 26.0 & - \\
\hline Kurata [31] & 2017 & Japan & 90 & $41(45.6)$ & $-/-1-$ & - & $31(34.4)$ & - & - & - & - \\
\hline Le [32] & 2017 & USA & 93 & 70/86 (81.3) & $93 / 0 / 0$ & - & $78(84.7)$ & - & $50(53.8)$ & 40.6 & - \\
\hline Watanabe [33] & 2017 & Japan & 122 & $98(87.5)$ & $73 / 47 / 2$ & $122(100)$ & $62(55.3)$ & - & $6(4.9)$ & 21 & 27 \\
\hline $\mathrm{Yu}$ [34] & 2017 & China & 93 & $32(34.4)$ & $-/-1-$ & 89 (96.6) & $49(52.6)$ & $52(55.9)$ & $36(38.7)$ & - & - \\
\hline
\end{tabular}

UK United Kingdom, PNI peri-neural invasion, TS tumor size, LNM lymph node metastasis, PTD poor tumor differentiation, MOS median overall survival, TR type of resection, $P D$ pancreaticoduodenectomy, $D P$ distal pancreatectomy, $T P$ total pancreatectomy, $R O R$ RO resection 
outcome was conducted to evaluate the presence of publication bias. The differences in clinicopathologic features were estimated as a pooled odds ratio (OR) with 95\% CI. All analyses were performed using the Review Manager 5.3 (Cochrane Collaboration, Software Update, Oxford). A value of $P<0.05$ was considered statistically significant.

\section{Results}

\section{Selection of studies}

A total of 28 studies comprising 23,945 individuals were identified for inclusion (Fig. 1). The summary characteristics of the included studies are shown in Table 1 [5, 6, 9-34]. There were no randomised controlled trials (RCT). All these studies were observational in nature and classified as level-4 evidence. There were 18 single-center $[5,9,10,12,13,15,17$, $19-21,23-28,32,33]$ and 10 multicenter studies [6, $11,14,16,18,22,29-31,34]$.

\section{Meta-analysis}

The impact of PDAC size on OS was evaluated in 26 studies $[5,6,9-13,15-18,20-34]$, among which univariate HR was reported in $14[5,6,10,11,21-25,28,30,31,34]$ and multivariate $H R$ was reported in $20[5,6,12,14-18$, $20,22,23,25-29,31-33]$. Both univariate and multivariate HR were reported in 8 studies $[5,6,20,22,23,25,28$, 31]. The pooled HR estimate for OS was 1.52 (95\% CI: $1.41-1.64 ; P<0.0001)$ by univariate analysis and 1.61 (95\% CI: $1.35-1.91 ; \quad P<0.0001)$ by multivariate analysis (Figs. 2-3). In sensitivity analysis, exclusion of any single study from the analysis did not alter the results significantly (data not shown). Also, the results from three subgroup analysis were in line with those from overall analyses (Table 2).

The impact of PDAC size on DFS was evaluated in 6 studies [18, 23-25, 28, 33], among which univariate HR was reported in $4[23-25,27]$ and multivariate HR was reported in $5[18,23,25,28,33]$. Both univariate and multivariate $\mathrm{HR}$ were reported in 3 studies $[23,25,28]$. The pooled HR estimate for DFS was 1.74 (95\% CI: $1.46-2.07 ; P<0.0001$ ) by univariate analysis and 1.38 (95\% CI: $1.12-1.68 ; P=0.002$ ) by multivariate analysis (Fig. 4a-b). Sensitivity and subgroup analyses were not performed due to the small number of studies.

Nine studies compared the clinicopathological factors between tumors $>2 \mathrm{~cm}$ and tumors $\leq 2 \mathrm{~cm}$ groups $[5,6,9,13,15,19,20,23,28]$. Pooled analysis showed that patients with tumor $>2 \mathrm{~cm}$ had higher incidences of lymph node metastasis $(79.1 \%$ vs. $64.2 \%$, OR 2.24, 95\% CI: 1.43-3.51; $P<0.001)$, poor tumor differentiation $(36.2 \%$ vs. $28.4 \%$, OR $1.45,95 \%$ CI: $1.22-1.73 ; P<0.001)$, perineural invasion $(80.8 \%$ vs. 67.1\%, OR $1.89,95 \%$ CI: $1.22-2.92 ; P=0.004)$, vascular invasion $(39.8 \%$ vs. $27.7 \%$, OR $1.78,95 \%$ CI: $1.41-$ 2.24; $P<0.001)$, positive resection margins $(36.9 \%$ vs. 27.2\%, OR 1.56, 95\% CI: $1.31-1.87 ; P<0.001)$, and positive intraoperative peritoneal cytology $(14.2 \%$ vs. 2.6\%, OR 5.66, 95\% CI: 2.15-14.93; $P<0.001)$, as compared with patients with tumors $\leq 2 \mathrm{~cm}$.

\section{Publication bias}

No significant funnel plot asymmetry was observed in the meta-analysis of univariate and multivariate OS (Fig. 5a-b).

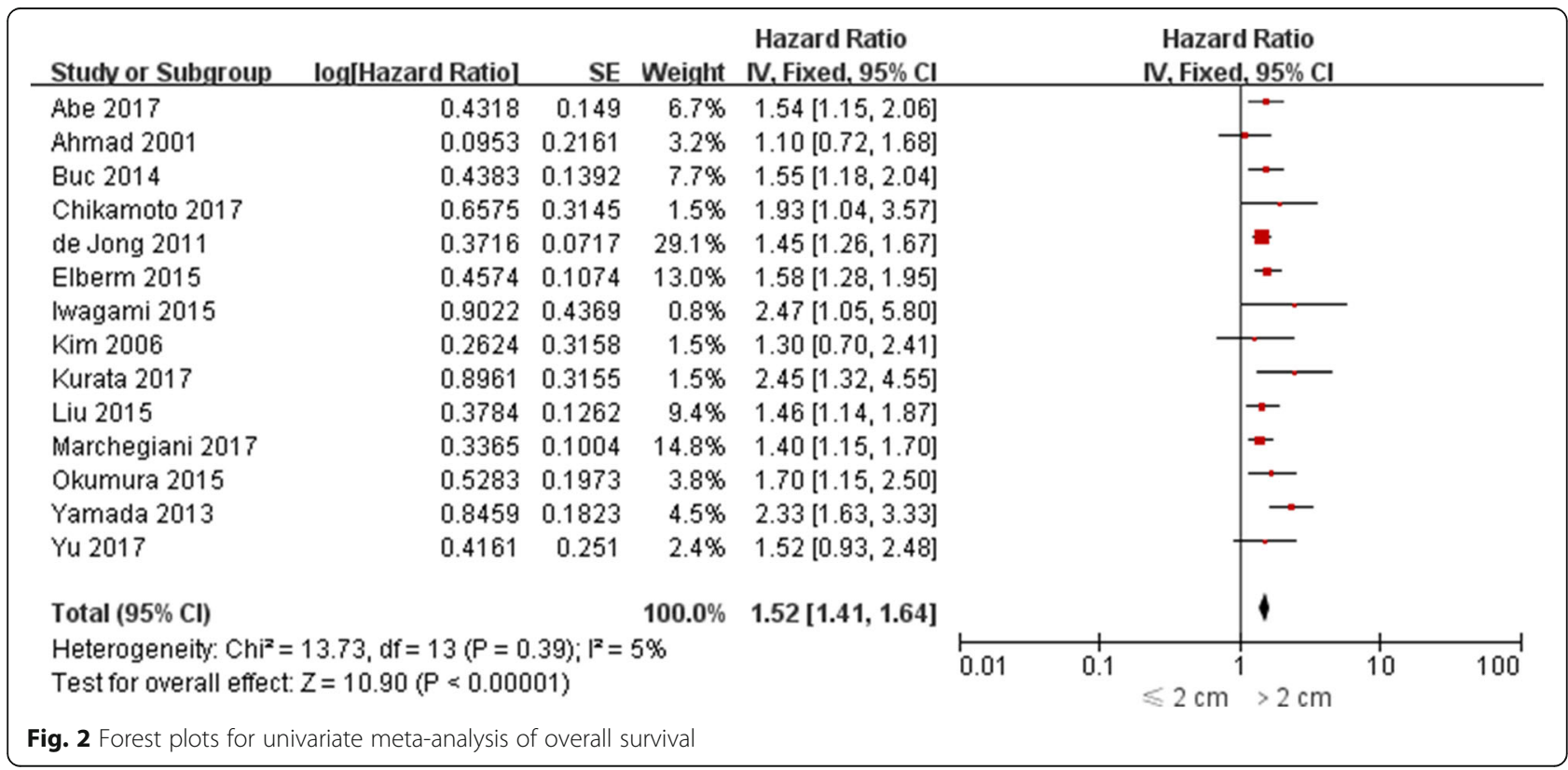




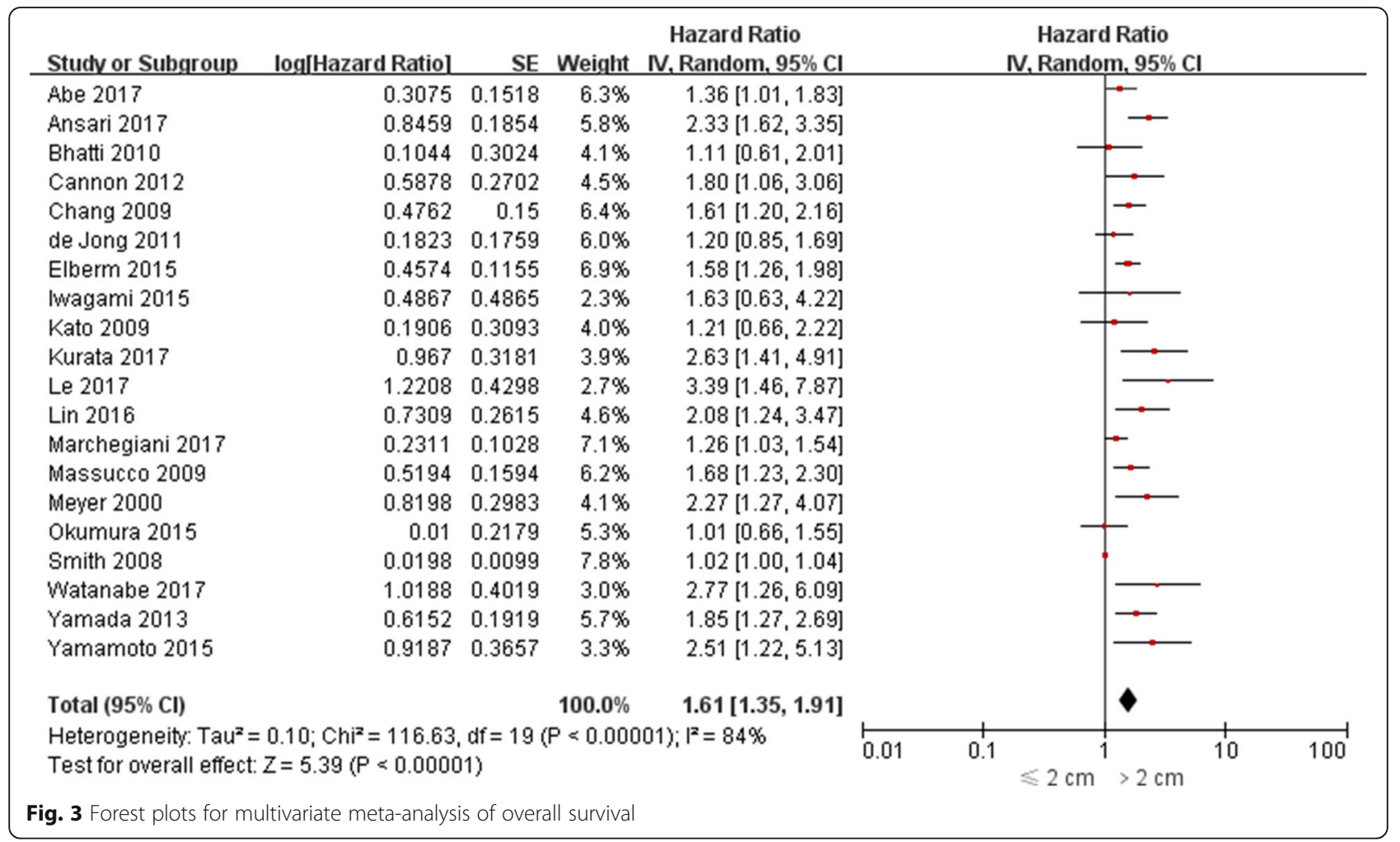

\section{Discussion}

Assessment of tumor size for prognostication had better reproducibility for both clinical and pathologic staging [35]. Indeed, many studies investigating the prognostic factors in PDAC have shown that tumor size is one of the most important parameters in predicting the clinical outcome of cancer patients. The cut-off point for PDAC size in the published reports varies from $2,2.5,3,4$, and $5 \mathrm{~cm} \mathrm{[6].} \mathrm{Generally,} \mathrm{tu-}$ mors $\leq 2 \mathrm{~cm}$ in the greatest dimension are defined as small PDAC [36]. Some authors noted that tumors $>2 \mathrm{~cm}$ have prognostic implications after resection $[6,12,14,16]$, while others failed to confirm this finding $[5,10,11]$. Meta-analysis provides a way to increase statistical power and resolves inconsistencies. Our pooling data have shown that tumors > $2 \mathrm{~cm}$ have negative impact on the survival of patients with PDAC. These findings affirm the validity of the T-stage of the current AJCC classification, in which the cut-off value of $2 \mathrm{~cm}$ is proposed to be the sole factor determining whether a pancreatic tumor is staged as T1 or T2 disease [4]. When the clinicopathologic findings in the two groups were compared, patients with tumors $>2 \mathrm{~cm}$ showed higher incidences of lymph node metastasis, poor tumor differentiation, lymph vessel invasion, vascular invasion, perineural invasion, positive resection margin, and positive intraoperative peritoneal cytology, implying that tumors $>2 \mathrm{~cm}$ intrinsically have more aggressive tumor biology that contributes to worse prognosis. Marchegiani et al. speculated that tumor size could be considered a surrogate of neoplastic progression, knowing that it is an expression

Table 2 Subgroup analysis for the influence of tumor size on overall survival after pancreatic ductal adenocarcinoma resection

\begin{tabular}{|c|c|c|c|c|c|}
\hline Subgroup & $\begin{array}{l}\text { No. of } \\
\text { studies }\end{array}$ & $\mathrm{HR}$ & $95 \% \mathrm{Cl}$ & $P$-value & $\mathrm{I}^{2}(\%)$ \\
\hline \multicolumn{6}{|l|}{ Single centre studies } \\
\hline Univariate analysis & 8 & 1.52 & $1.39,1.67$ & $<0.001$ & 29 \\
\hline Multivariate analysis & 13 & 1.53 & $1.22,1.91$ & $<0.001$ & 76 \\
\hline \multicolumn{6}{|l|}{ Multicentre studies } \\
\hline Univariate analysis & 7 & 1.54 & $1.36,1.74$ & $<0.001$ & 0 \\
\hline Multivariate analysis & 7 & 1.67 & $1.41,1.99$ & $<0.001$ & 51 \\
\hline \multicolumn{6}{|l|}{ Western studies } \\
\hline Univariate analysis & 8 & 1.46 & $1.34,1.59$ & $<0.001$ & 0 \\
\hline Multivariate analysis & 11 & 1.55 & $1.25,1.92$ & $<0.001$ & 87 \\
\hline \multicolumn{6}{|l|}{ Eastern studies } \\
\hline Univariate analysis & 7 & 1.82 & $1.55,2.15$ & $<0.001$ & 0 \\
\hline Multivariate analysis & 10 & 1.62 & $1.40,1.87$ & $<0.001$ & 35 \\
\hline
\end{tabular}

$\mathrm{Cl}$ confidence interval, $H R$ hazard ratio 


\begin{tabular}{|c|c|c|c|c|c|c|c|c|c|c|c|}
\hline a. & Study or Subgroup & log[Hazard Ratio] & SE & Weight & $\begin{array}{c}\text { Hazard Ratio } \\
\text { IV, Fixed, 95\% Cl }\end{array}$ & & & $\begin{array}{r}\text { Hazard } \\
\text { N, Fixed }\end{array}$ & $\begin{array}{l}\text { Ratio } \\
95 \% \mathrm{Cl}\end{array}$ & & \\
\hline & Abe 2017 & 0.8372 & 0.1906 & $21.8 \%$ & $2.31[1.59,3.36]$ & & & & $\rightarrow-$ & & \\
\hline & Iwagami 2015 & 1.0578 & 0.4102 & $4.7 \%$ & $2.88[1.29,6.44]$ & & & & & & \\
\hline & Liu 2015 & 0.4318 & 0.1273 & $48.8 \%$ & $1.54[1.20,1.98]$ & & & & 다 & & \\
\hline & Okumura 2015 & 0.4536 & 0.1787 & $24.8 \%$ & $1.57[1.11,2.23]$ & & & & $\rightarrow-$ & & \\
\hline & Total $(95 \% \mathrm{Cl})$ & & & $100.0 \%$ & $1.74[1.46,2.07]$ & & & & $\boldsymbol{\imath}$ & & \\
\hline & $\begin{array}{l}\text { Heterogeneity: } \mathrm{Chi}^{2}= \\
\text { Test for overall effect }\end{array}$ & $\begin{array}{l}4.95, d f=3(P=0.18 \\
Z=6.24(P<0.0000\end{array}$ & 3); $\left.\right|^{2}=39$ & & & 0.01 & 0.1 & $\leqslant 2 \mathrm{~cm}^{1}$ & $>2 \mathrm{~cm}$ & 10 & 100 \\
\hline$b$ & Study or Subgroup & log[Hazard Ratio] & SE & Weight & $\begin{array}{l}\text { Hazard Ratio } \\
\text { IV, Fixed, 95\% Cl }\end{array}$ & & & $\begin{array}{r}\text { Hazard } \\
\text { IV, Fixed }\end{array}$ & $\begin{array}{l}\text { Ratio } \\
\text { 1, } 95 \% \mathrm{Cl}\end{array}$ & & \\
\hline & Abe 2017 & 0.3784 & 0.2086 & $24.2 \%$ & $1.46[0.97,2.20]$ & & & & - & & \\
\hline & Cannon 2012 & 0.2776 & 0.1678 & $37.4 \%$ & $1.32[0.95,1.83]$ & & & & - & & \\
\hline & Iwagami 2015 & 1.0438 & 0.5225 & $3.9 \%$ & $2.84[1.02,7.91]$ & & & & & & \\
\hline & Okumura 2015 & 0.0478 & 0.1927 & $28.3 \%$ & $1.05[0.72,1.53]$ & & & - & - & & \\
\hline & Watanabe 2017 & 1.1086 & 0.4087 & $6.3 \%$ & $3.03[1.36,6.75]$ & & & & & & \\
\hline & Total $(95 \% \mathrm{Cl})$ & & & $100.0 \%$ & $1.38[1.12,1.68]$ & & & & $\bullet$ & & \\
\hline & $\begin{array}{l}\text { Heterogeneity: } \mathrm{Chi}^{2}= \\
\text { Test for overall effect }\end{array}$ & $\begin{array}{l}7.78, d f=4(P=0.10 \\
Z=3.11(P=0.002)\end{array}$ & $0) ; 1^{2}=49$ & & & 0.01 & 0.1 & $\leqslant 2 \mathrm{~cm}^{1}$ & $>2 \mathrm{~cm}$ & 10 & 100 \\
\hline
\end{tabular}

of time passing from its original development. Therefore, a tumor with bigger dimensions often implies a relatively delayed diagnosis and therefore has a higher likelihood of being associated with other adverse pathologic factors [6].

The PDAC size also has impact on operative outcomes. Patients with tumors $>2 \mathrm{~cm}$ were found to be associated with more intra-operative blood loss and a greater need for packed red blood cell transfusion [5], knowing that the latter variable may lead to worse oncologic outcomes via transfusion-related immune modulation [37].

There is growing evidence that neoadjuvant therapy is associated with a statistically significant reduction in the tumor positive margin status, tumor stage and grade, lymph node metastasis, and perineural invasion, thereby resulting in improved survival in patients with initially resectable PDAC [38]. However, identification of patients who will benefit from neoadjuvant therapy remains challenging. Unlike other malignant pathological features of PDAC, tumor size can be diagnosed by preoperative imaging and therefore may be able to guide clinical decision making. Our results show that tumors $>2 \mathrm{~cm}$ are characterized by the presence of other relevant poor prognostic factors and therefore can be considered as an indication for neoadjuvant therapy. The potential aim is to achieve dual purposes of attenuating malignant pathological features

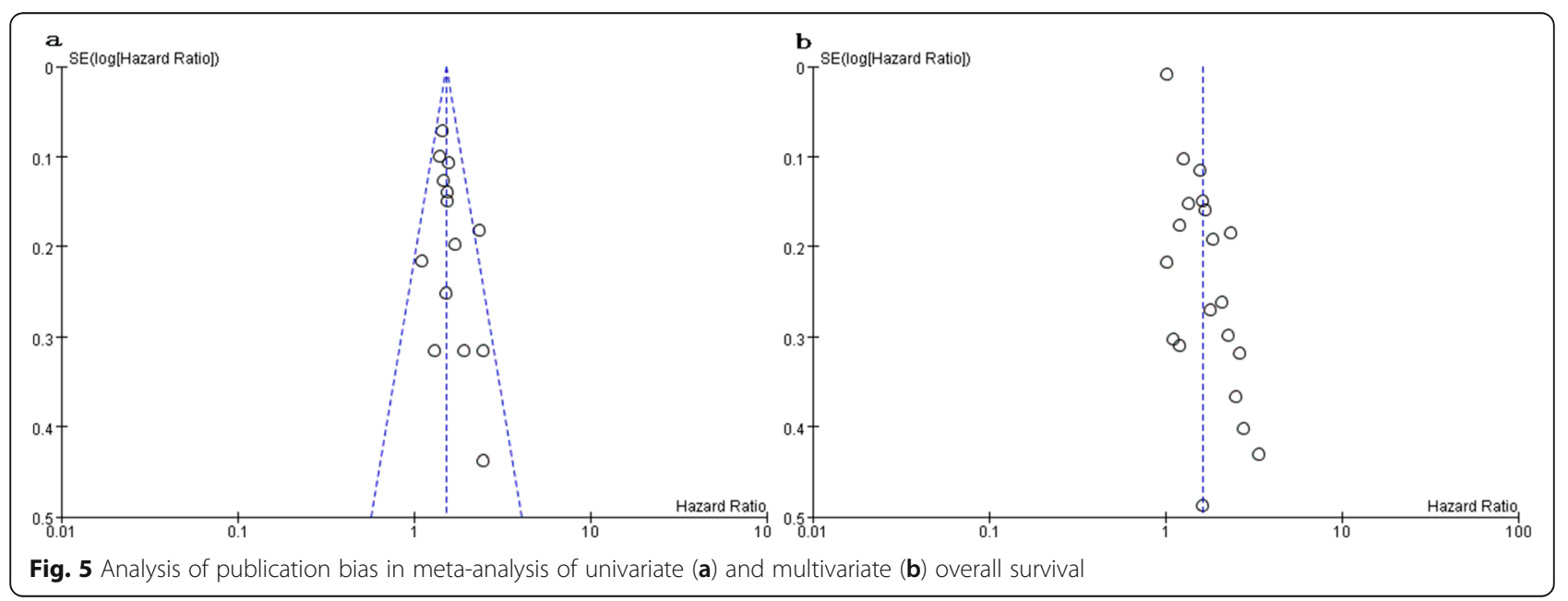


on the one hand and improving the surgical outcome on the other. Randomized controlled trials are necessary to confirm this preliminary recommendation.

This review is limited by the low quality. All included studies were retrospective in nature and classified as level-4 evidence, which underlines the validity of the analyzed outcomes. Ansari et al. [29] found that the association between survival and PDAC size was linear in patients with localized tumors but stochastic in patients with regional and distant stages. Unfortunately, none of the included studies analysed the stage-dependent relationship between PDAC size and survival. Similarly, subgroup analysis based on anatomic location of the PDAC could not be performed due to insufficient data.

The strength of our findings is that it represents a variety of clinical settings, including Eastern and Western data rather than the sole experience of a single institution. In addition, these pooled results based on multivariate analysis do not differ essentially from those of analyses based on univariate analysis. These findings indicate that tumors $>2 \mathrm{~cm}$, per se rather than a confounder, have a prognostic implication. Finally, there is no evidence of publication bias.

\section{Conclusion}

The current evidence demonstrates that PDAC size > $2 \mathrm{~cm}$ is an independent predictive factor for poor prognosis after surgical resection and associated with more aggressive tumor biology. Future trials are necessary to evaluate the survival benefit of neoadjuvant therapy in this subset of patients.

\section{Abbreviations \\ 95\% Cl: 95\% confidence interval; DFS: Disease-free survival; DM: Diabetes mellitus; HR: Hazard ratio; OR: Odds ratio; OS: Overall survival; \\ PDAC: Pancreatic ductal adenocarcinoma; PRISMA: Preferred reporting items for systematic reviews and meta-analyses; WMD: Weighted mean difference}

\section{Acknowledgements}

We thank Doctor Yanfang Zhao (Department of Health Statistics, Second Military Medical University, Shanghai, China) for her critical revision of the meta-analysis section.

\section{Funding}

The project was supported by Natural Science Foundation of Fujian province (2015 J01561) and Major Diseases Joint Research Program of Xiamen City (3502Z20170943).

\section{Availability of data and materials}

Input data for the analyses are available from the corresponding author on request.

\section{Authors' contributions}

$L D, H B$ and $Z Y$ participated in the design and coordination of the study, carried out the critical appraisal of studies and wrote the manuscript. HB, WT, and XS developed the literature search, carried out the extraction of data, assisted in the critical appraisal of included studies and assisted in writing up, WT and YZ carried out the statistical analysis of studies. All authors read and approved the final manuscript.

\section{Competing interest}

The authors declare that they have no competing interests.

Ethics approval and consent to participate

Not applicable.

Consent for publication

Not applicable.

\section{Publisher's Note}

Springer Nature remains neutral with regard to jurisdictional claims in published maps and institutional affiliations.

\section{Author details}

1Department III of General Surgery, First Hospital of Lanzhou University, Lanzhou, China. ${ }^{2}$ Department of Clinical Laboratory Medicine, First affiliated Hospital of Xiamen University, Xiamen, China. ${ }^{3}$ Department of Hepatobiliary \& Pancreatovascular Surgery, First affiliated Hospital of Xiamen University, Xiamen, China.

Received: 6 October 2017 Accepted: 4 October 2018

Published online: 16 October 2018

\section{References}

1. Strobel O, Hinz U, Gluth A, Hank T, Hackert T, Bergmann F, et al. Pancreatic adenocarcinoma: number of positive nodes allows to distinguish several $\mathrm{N}$ categories. Ann Surg. 2015;261:961-9. https://doi.org/10.1097/SLA. 0000000000000814

2. Wagner M, Redaelli C, Lietz M, Seiler CA, Friess H, Büchler MW. Curative resection is the single most important factor determining outcome in patients with pancreatic adenocarcinoma. Br J Surg. 2004;91:586-94. https:// doi.org/10.1002/bjs.4484

3. Crippa S, Partelli S, Zamboni G, Barugola G, Capelli P, Inama M, et al. Poorly differentiated resectable pancreatic cancer: is upfront resection worthwhile? Surgery. 2012;152:S112-9. https://doi.org/10.1016/j.surg.2012.05.017.

4. Allen PJ, Kuk D, Castillo CF, Basturk O, Wolfgang CL, Cameron JL, et al. Multi-institutional validation study of the American joint commission on Cancer (8th edition) changes for T and $\mathrm{N}$ staging in patients with pancreatic adenocarcinoma. Ann Surg. 2017;265:185-91. https://doi.org/10 1097/SLA.0000000000001763.

5. de Jong MC, Li F, Cameron JL, Wolfgang CL, Edil BH, Herman JM, et al. Re-evaluating the impact of tumor size on survival following pancreaticoduodenectomy for pancreatic adenocarcinoma. J Surg Oncol. 2011;103:656-62. https://doi.org/10.1002/jso.21883.

6. Marchegiani G, Andrianello S, Malleo G, De Gregorio L, Scarpa A, MinoKenudson $\mathrm{M}$, et al. Does size matter in pancreatic Cancer?: reappraisal of tumour dimension as a predictor of outcome beyond the TNM. Ann Surg. 2017;266:142-8. https://doi.org/10.1097/SLA.0000000000001837.

7. Moher D, Liberati A, Tetzlaff J, Altman DG. PRISMA group: preferred reporting items for systematic reviews and meta-analyses: the PRISMA statement. BMJ. 2009:339:b2535.

8. Zhu JC, Yan TD, Morris DL. A systematic review of radiofrequency ablation for lung tumors. Ann Surg Oncol. 2008;15:1765-74. https://doi.org/10.1245/ s10434-008-9848-7.

9. Meyer W, Jurowich C, Reichel M, Steinhäuser B, Wünsch PH, Gebhardt C. Pathomorphological and histological prognostic factors in curatively resected ductal adenocarcinoma of the pancreas. Surg Today. 2000;30: 582-7. https://doi.org/10.1007/s005950070096.

10. Ahmad NA, Lewis JD, Ginsberg GG, Haller DG, Morris JB, Williams NN, et al. Long term survival after pancreatic resection for pancreatic adenocarcinoma. Am J Gastroenterol. 2001;96:2609-15. https://doi.org/ 10.1111/j.1572-0241.2001.04123.x.

11. Kim J, Reber HA, Dry SM, Elashoff D, Chen SL, Umetani N, et al. Unfavourable prognosis associated with K-ras gene mutation in pancreatic cancer surgical margins. Gut. 2006;55:1598-605. https://doi. org/10.1136/gut.2006.098814.

12. Smith RA, Bosonnet $L$, Ghaneh $P$, Raraty $M$, Sutton $R$, Campbell $F$, et al. Preoperative CA19-9 levels and lymph node ratio are independent predictors of survival in patients with resected pancreatic ductal adenocarcinoma. Dig Surg. 2008;25:226-32. https://doi.org/10.1159/000140961. 
13. Chang DK, Johns AL, Merrett ND, Gill AJ, Colvin EK, Scarlett CJ, et al Margin clearance and outcome in resected pancreatic cancer. J Clin Oncol. 2009;27:2855-62. https://doi.org/10.1200/JCO.2008.20.5104.

14. Chiang KC, Yeh CN, Lee WC, Jan YY, Hwang TL. Prognostic analysis of patients with pancreatic head adenocarcinoma less than $2 \mathrm{~cm}$ undergoing resection. World J Gastroenterol. 2009;15:4305-10. https:// doi.org/10.3748/wjg.15.4305

15. Kato K, Yamada S, Sugimoto H, Kanazumi N, Nomoto S, Takeda S, et al. Prognostic factors for survival after extended pancreatectomy for pancreatic head cancer: influence of resection margin status on survival. Pancreas. 2009;38:605-12. https://doi.org/10.1097/MPA.0b013e3181a4891d.

16. Massucco P, Ribero D, Sgotto E, Mellano A, Muratore A, Capussotti L. Prognostic significance of lymph node metastases in pancreatic head cancer treated with extended lymphadenectomy: not just a matter of numbers. Ann Surg Oncol. 2009;16:3323-32. https://doi.org/10.1245/s10434-009-0672-5.

17. Bhatti I, Peacock O, Awan AK, Semeraro D, Larvin M, Hall RI. Lymph node ratio versus number of affected lymph nodes as predictors of survival for resected pancreatic adenocarcinoma. World J Surg. 2010;34:768-75. https:// doi.org/10.1007/s00268-009-0336-4

18. Cannon RM, LeGrand R, Chagpar RB, Ahmad SA, McClaine R, Kim HJ, et al. Multi-institutional analysis of pancreatic adenocarcinoma demonstrating the effect of diabetes status on survival after resection. HPB (Oxford). 2012;14: 228-35. https://doi.org/10.1111/j.1477-2574.2011.00432.x.

19. Petermann D, Demartines $N$, Schäfer $M$. Is tumour size an underestimated feature in the current TNM system for malignancies of the pancreatic head? HPB (Oxford). 2013;15:872-81. https://doi.org/10.1111/hpb.12052.

20. Yamada S, Fujii T, Kanda M, Sugimoto H, Nomoto S, Takeda S, et al. Value of peritoneal cytology in potentially resectable pancreatic cancer. Br J Surg. 2013;100:1791-6. https://doi.org/10.1002/bjs.9307.

21. Buc E, Couvelard A, Kwiatkowski F, Dokmak S, Ruszniewski P, Hammel P, et al. Adenocarcinoma of the pancreas: does prognosis depend on mode of lymph node invasion? Eur J Surg Oncol. 2014;40:1578-85. https://doi.org/10. 1016/j.ejso.2014.04.012.

22. Elberm H, Ravikumar R, Sabin C, Abu Hilal M, Al-Hilli A, Aroori S, et al. Outcome after pancreaticoduodenectomy for T3 adenocarcinoma: a multivariable analysis from the UK vascular resection for pancreatic Cancer study group. Eur J Surg Oncol. 2015;41:1500-7. https://doi.org/10.1016/j.ejso.2015.08.158.

23. Iwagami $Y$, Equchi $H$, Wada $H$, Tomimaru $Y$, Hama $N$, Kawamoto $K$, et al. Implications of peritoneal lavage cytology in resectable left-sided pancreatic cancer. Surg Today. 2015;45:444-50. https://doi.org/10.1007/s00595-014-0964-7.

24. Liu L, Katz MH, Lee SM, Fischer LK, Prakash L, Parker N, et al. Superior mesenteric artery margin of Posttherapy Pancreaticoduodenectomy and prognosis in patients with pancreatic ductal adenocarcinoma. Am J Surg Pathol. 2015;39:1395-403. https://doi.org/10.1097/PAS.0000000000000491.

25. Okumura S, Kaido T, Hamaguchi Y, Fujimoto Y, Masui T, Mizumoto M, et al. Impact of preoperative quality as well as quantity of skeletal muscle on survival after resection of pancreatic cancer. Surgery. 2015;157:1088-98. https://doi.org/10.1016/j.surg.2015.02.002.

26. Yamamoto T, Yagi S, Kinoshita H, Sakamoto Y, Okada K, Uryuhara K, et al. Long-term survival after resection of pancreatic cancer: a single-cente retrospective analysis. World J Gastroenterol. 2015;21:262-8. https://doi.org/ 10.3748/wjg.v21.i1.262

27. Lin JY, Zhang XM, Kou JT, Fa H, Zhang XX, Dai Y, He Q. Analysis of prognostic factors for pancreatic head cancer according to Para-aortic lymph node. Cancer Med. 2016;5:2701-7. https://doi.org/10.1002/cam4.853.

28. Abe T, Ohuchida K, Endo S, Ookubo F, Mori Y, Nakata K, et al. Clinical importance of intraoperative peritoneal cytology in patients with pancreatic cancer. Surgery. 2017;161:951-8. https://doi.org/10.1016/j.surg.2016.10.035.

29. Ansari D, Bauden M, Bergström S, Rylance R, Marko-Varga G, Andersson R. Relationship between tumour size and outcome in pancreatic ductal adenocarcinoma. Br J Surg. 2017;104:600-7. https://doi.org/10.1002/bjs.10471.

30. Chikamoto A, Inoue R, Komohara Y, Sakamaki K, Hashimoto D, Shiraishi S, et al. Preoperative high maximum standardized uptake value in association with glucose transporter 1 predicts poor prognosis in pancreatic Cancer. Ann Surg Oncol. 2017;24:2040-6. https://doi.org/10.1245/s10434-017-5799-1.

31. Kurata M, Honda G, Murakami Y, Uemura K, Satoi S, Motoi F, et al. Multicenter study Group of Pancreatobiliary Surgery (MSG-PBS): retrospective study of the correlation between pathological tumor size and survival after curative resection of T3 pancreatic adenocarcinoma: proposal for reclassification of the tumor extending beyond the pancreas based on tumor size. World I Surg. 2017 Jun 15. https://doi.org/10.1007/s00268-017-4077-5.
32. Le AT, Huang B, Hnoosh D, Saeed H, Dineen SP, Hosein PJ, Durbin EB, et al. Effect of complications on oncologic outcomes after pancreaticoduodenectomy for pancreatic cancer. J Surg Res. 2017;214:1-8. https://doi.org/10.1016/j.jss.2017.02.036.

33. Watanabe Y, Nishihara K, Matsumoto S, Okayama T, Abe Y, Nakano T. Effect of postoperative major complications on prognosis after pancreatectomy for pancreatic cancer: a retrospective review. Surg Today. 2017;47:555-67. https://doi.org/10.1007/s00595-016-1426-1.

34. Yu R, Li C, Lin X, Chen Q, Li J, Song L, et al. Clinicopathologic features and prognostic implications of MYBL2 protein expression in pancreatic ductal adenocarcinoma. Pathol Res Pract. 2017;213:964-8. https://doi.org/10.1016/j. prp.2017.04.024

35. Morganti AG, Brizi MG, Macchia G, Sallustio G, Costamagna G, Alfieri S, et al. The prognostic effect of clinical staging in pancreatic adenocarcinoma. Ann Surg Oncol. 2005:12:145-51. https://doi.org/10.1245/ASO.2005.02.021.

36. Agarwal B, Correa AM, Ho L. Survival in pancreatic carcinoma based on tumor size. Pancreas. 2008;36:e15-20. https://doi.org/10.1097/mpa. Ob013e31814de421.

37. Dusch N, Weiss C, Ströbel P, Kienle P, Post S, Niedergethmann M. Factors predicting long-term survival following pancreatic resection for ductal adenocarcinoma of the pancreas: 40 years of experience. J Gastrointest Surg. 2014:18:674-81. https://doi.org/10.1007/s11605-013-2408-x.

38. Schorn S, Demir IE, Reyes CM, Saricaoglu C, Samm N, Schirren R, et al. The impact of neoadjuvant therapy on the histopathological features of pancreatic ductal adenocarcinoma - a systematic review and meta-analysis. Cancer Treat Rev. 2017;55:96-106. https://doi.org/10.1016/j.ctrv.2017.03.003.

\section{Ready to submit your research? Choose BMC and benefit from:}

- fast, convenient online submission

- thorough peer review by experienced researchers in your field

- rapid publication on acceptance

- support for research data, including large and complex data types

- gold Open Access which fosters wider collaboration and increased citations

- maximum visibility for your research: over $100 \mathrm{M}$ website views per year

At $\mathrm{BMC}$, research is always in progress.

Learn more biomedcentral.com/submissions 